\title{
Tubular gastric herniation and lower oesophageal strictures
}

\author{
OSCAR CRAIG \\ From the Department of Radiodiagnosis, St. Mary's Hospital, London W.2, and \\ Harefield Hospital, Middlesex
}

The role of the lower oesophagus lined by 'columnar epithelium' in producing oesophageal strictures was described by Barrett in 1950. At that time he considered this part of the gullet to be functionally an intrathoracic stomach. However, in 1953, Allison and Johnstone gave reasons for considering this finding to be a congenital anomaly of the oesophagus and not an intrathoracic stomach. Their arguments were that (1) the tubular structure, resembling the oesophagus grossly, had no peritoneal covering as did the stomach; (2) the submucosa had mucous glands and the musculature was that of the oesophagus; and (3) islets of squamous epithelium were found within the sheet of gastric glands, and no acid-producing oxyntic cells were found in this area.

In 1957 Barrett adopted this viewpoint and described the lower oesophagus lined by columnar epithelium as a congenital anomaly. In these cases there is frequently an associated hiatus hernia below the columnar-lined segment. This hernia is usually saccular in shape and can be readily recognized. It terminates well below any stricture that may be present.

It is the purpose of this paper to describe 10 cases of lower oesophageal stricture in which the lower gullet, although tubular in shape, is actually a stomach herniation, which extends to a point directly below the stricture. These patients bear a close resemblance to those who have a lower oesophagus lined by columnar epithelium and would readily be misdiagnosed as having columnar mucosa in the oesophagus if the total extent of the herniation were overlooked.

This tubular-shaped hernia radiologically resembles the oesophagus. That the stomach can resemble the oesophagus when placed in the chest is often noted after oesophagectomy and gastric anastomosis. The sleeve of intrathoracic stomach becomes more tubular as time progresses.

In the 10 cases reported here there is operative or biopsy proof, or both, that the gastric hernia- tion extended in tubular shape right to the level of the stricture. Although some of the strictures were misdiagnosed originally as carcinoma, in all it would also be possible to confuse them with the Barrett syndrome. Radiologically, when the barium swallow films are taken in the erect or supine positions without abdominal compression or suitable posturing, the lower end of the gullet below the stricture will not distend and the true extent or even the presence of a hernia will be overlooked. Conversely, with suitable posturing and the use of abdominal compression, the presence of gastric herniation and its extension in tubular form to a point just below the stricture will be appreciated.

\section{CASE REPORTS}

CASE 1 L.F., a man aged 66, presented on 17 March 1964 with a history of gradually increasing dysphagia for the past 18 months. He developed a retrosternal bursting pain during swallowing and had then begun to vomit. He had vomited dark blood on a few occasions. There was no past history of indigestion. A barium meal examination performed at another hospital before this admission was reported as showing a stricture at the junction of the middle and lower thirds of the oesophagus suggestive of a neoplasm.

Barium meal (17 April 1964) (Fig. 1) There is a stricture in the lower third of the gullet, in what appears to be the junction of the middle and lower thirds of the oesophagus. However, the lower third of the gullet has the characteristics of the stomach and is considered to be a tubular hiatus hernia.

Oesophagoscopy The stricture was seen at $35 \mathrm{~cm}$. A biopsy was taken just below this and a further one was taken at the stricture.

Biopsy The epithelium of the biopsy below the stricture is columnar and is gastric mucosa. No evidence of malignancy is seen from either site. 


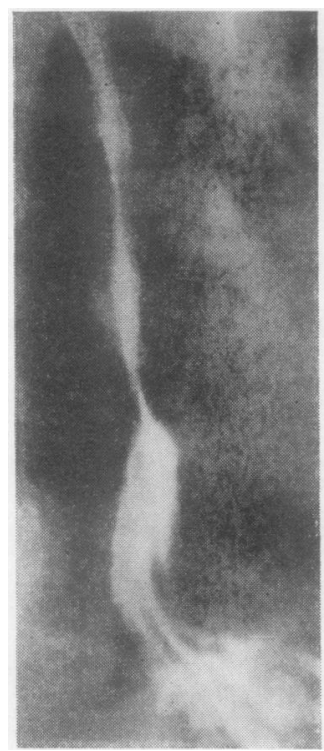

FIG. 1. Case 1. Lower oesophageal stricture. The hernia is becoming tubular but the mucosal folds above the diaphragm are gastric in appearance.

Operation A sliding hiatus hernia was found. This extended to the level of the stricture. The hernia just above the diaphragm is very obvious on the films taken at Harefield Hospital, but its extension to the stricture level is perhaps less obvious.

CASE 2 A.W., a man aged 67, noticed tiredness on exertion in June 1962. Investigation elsewhere had revealed a severe iron-deficiency anaemia. He presented at this hospital on 15 February 1963. There was a history of intermittent indigestion, heartburn, and acid regurgitation. He complained of increasing dysphagia, and the food was felt to stick in the lower part of the chest.

Oesophagoscopy (21 February 1963) A stricture was found at $31 \mathrm{~cm}$. A neoplasm was considered a possibility, and a biopsy was taken.

Barium meal (1 March 1963) (Fig. 2) There is a stricture in the gullet below the level of the lung roots. Below this level the passage is slightly wider, and its lining suggests gastric mucosa. The appearances are considered to be due to peptic oesophagitis with 'shortening of the oesophagus'.

Biopsy The ulcerated area is covered by chronic inflammatory granulation tissue. Above this the mucosa is oesophageal, and below this it is gastric in type.

Operation (8 April 1963) A sliding hiatus hernia was found extending to the stricture.

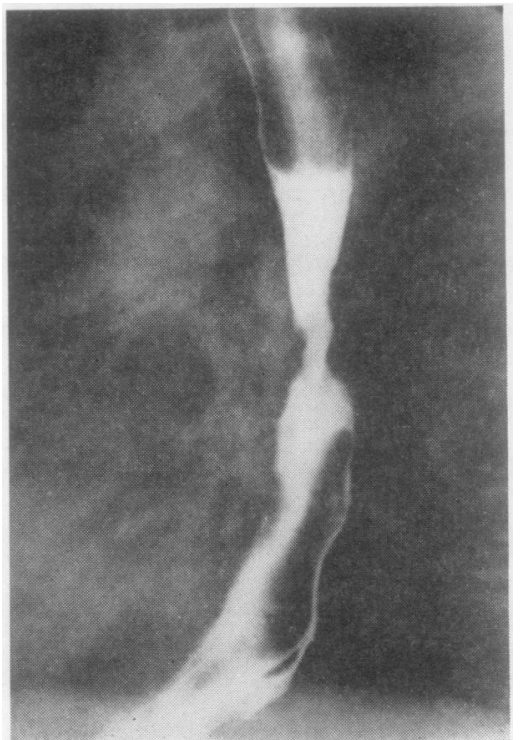

FIG. 2. Case 2. Irregular stricture in the oesophagus. The gullet below this is slightly wider than the oesophagus above.

CASE 3 H.H., a man aged 76, was transferred to Hare- 릉 field Hospital from elsewhere on 25 March 1964 with $\frac{1}{8}$ a history of dysphagia for the past year, which was gradually getting worse. There was no past history of indigestion and no heartburn. A barium swallow (Fig. 3) elsewhere had shown a stricture in the lower end

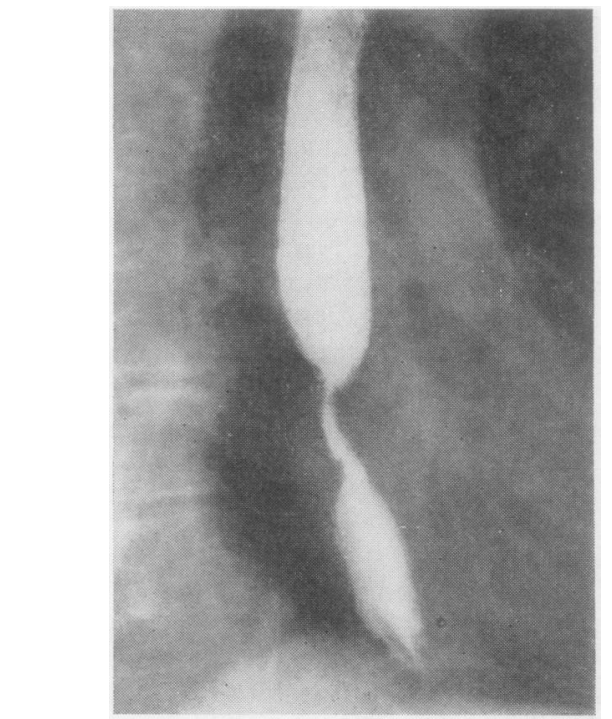

FIG. 3. Case 3. Irregular stricture very like a malignant lesion, with tubular herniation below it. 
of the oesophagus. It had irregular margins and tapered over a distance of $1.5 \mathrm{~cm}$. The appearances resembled a carcinoma of the oesophagus or possibly a benign stricture. There was no record of reflux in the report.

Oesophagoscopy This revealed a stricture at $35 \mathrm{~cm}$. A biopsy was taken.

Biopsy This revealed ulceration and inflammatory changes. The mucosa below this was gastric in type and reported as being 'ectopic gastric mucosa' in the oesophagus.

A further oesophagoscopy was performed and, although it was considered that a malignant lesion had not been completely excluded, it was thought likely that the stricture was secondary peptic oesophagitis following reflux from a hernia.

Operation A sliding hiatus hernia was found extending to the stricture.

CASE 4 E.G., a man aged 74, presented on 22 September 1964, complaining of food sticking in the throat for one year. There was a past history of regurgitation of food.

Barium swallow (Fig. 4) This revealed a stricture and a small ulcer about 2 in. ( $50 \mathrm{~mm}$.) above the diaphragm with irregular walls. The possibility of a neoplasm was considered, but there was some reflux, and the gullet below the stricture was thought to be gastric. A benign stricture was considered to be the likely diagnosis.

Oesophagoscopy (24 September 1964) An irregular haemorrhagic stricture was seen at $35 \mathrm{~cm}$. Biopsies were taken.

Biopsy At $34 \mathrm{~cm}$. there was oesophageal mucosa. At $35 \mathrm{~cm}$. a stricture area was seen with marked chronic

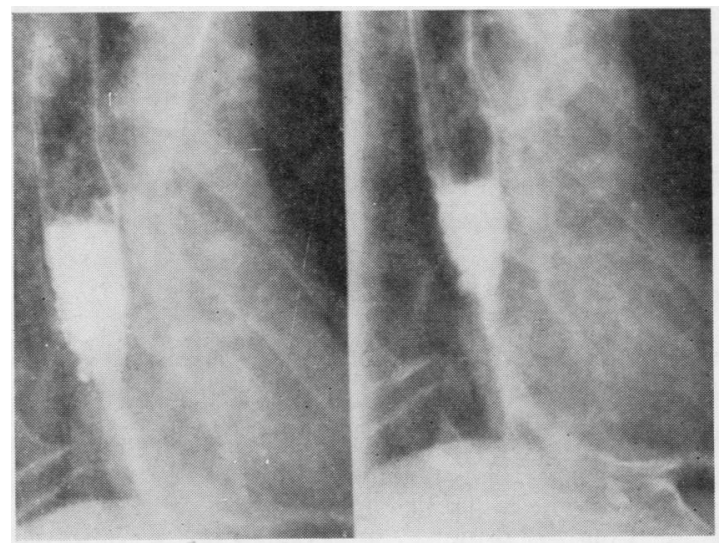

FIG. 4. Case 4. Stricture with ulceration. The hernia below this is very tubular. inflammatory changes but no malignancy. At $42 \mathrm{~cm}$. there was gastric mucosa.

Operation A hiatus hernia was found extending right up to the stricture. At the site of the stricture there was considerable peri-oesophageal fibrosis.

CASE 5 W.W., a man aged 69, gave a history of difficulty in swallowing 10 years previously which had improved spontaneously. The patient presented on 27 May 1964 as the dysphagia had recurred and was getting more severe. Before this he had experienced regurgitation from the stomach when lying down.

A barium meal (Fig. 5) had been performed elsewhere, and the report read: 'a localized stricture in the lower third of the oesophagus, probably associated with a small hiatus hernia'. There was no record of reflux.

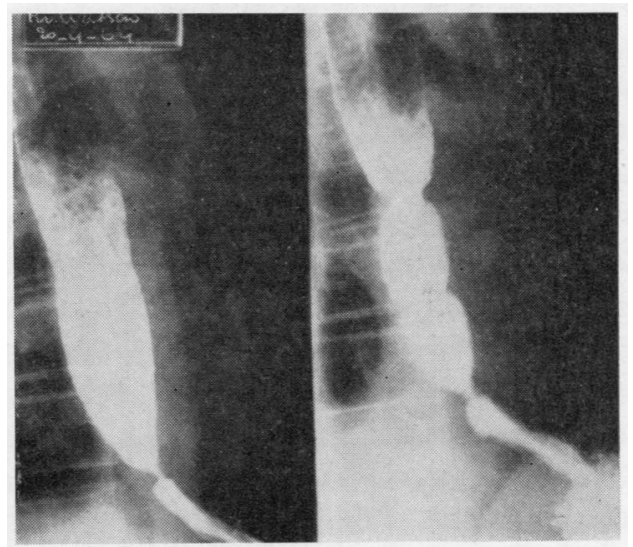

FIG. 5. Case 5. Very tight stricture with narrow tubular herniation. The segmental division of the gullet was entirely due to peristaltic waves.

Oesophagoscopy (27 May 1964) A tight stricture was encountered at $40 \mathrm{~cm}$. A biopsy was taken.

Biopsy The mucosa consists of normal oesophageal epithelium.

On one of the films there appear to be three segments in the lower end of the gullet. These are similar to those discussed by Allison and Johnstone (1953) and named as oesophagus, gastric-lined oesophagus, and herniated stomach, from above downwards.

If this were so in this patient, then the stricture would lie between the herniated stomach and the ectopic gastric mucosa. As the biopsy taken just above the stricture was reported as oesophageal mucosa this segmental anatomy does not apply. The portion of the gullet below the stricture was gastric and due to a tubularshaped hernia.

Operation A tubular hernia was found and repaired. It extended to just below the stricture. 
CASE 6 M.K., a woman aged 73, presented on 7 July 1964 with a history of indigestion on and off for years. Two months before her admission she had noticed food sticking at the level of the lower end of the sternum. The discomfort was caused mainly by solid foods : semi-solid foods gave much less trouble.

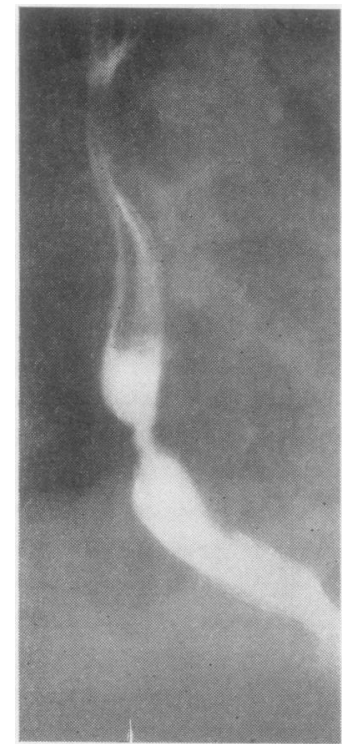

FIG. 6. Case 6. A tight stricture lying just above a tubular hiatus hernia.

A barium meal (Fig. 6) elsewhere had revealed a stricture in the lower third of the gullet. It was thought that this was a simple stricture and due to peptic oesophagitis.

Oesophagoscopy (9 July 1964) The stricture was seen at $34 \mathrm{~cm}$. A bougie was passed, followed by the oesophagoscope into the stomach. A biopsy was taken at $34 \mathrm{~cm}$.

Biopsy There are chronic inflammatory changes in the oesophageal mucosa. No malignancy is seen.

Operation A large sliding hiatus hernia was found, and it was tubular in shape right up to the stricture.

CASE 7 G.W.. a woman aged 68, presented on 10 September 1964 with a history of dysphagia. She had a 'blocked feeling' in the throat, which worked up from the sternal level. This was of recent onset but was getting worse. There was no past history of indigestion and no vomiting.

Oesophagoscopy (11 September 1964) At the middle third of the gullet there was a narrowing, above which some oesophagitis was seen. The mucosa elsewhere was normal.
Barium meal (18 September 1964) (Fig. 7) The stricture was seen in the middle third of the gullet. Below the $\frac{\omega}{\partial}$ stricture the gullet represents a hiatus hernia, which is tubular in shape. The stricture no doubt results from reflux oesophagitis. There was no reflux into the lower ${ }^{\infty}$ gullet.

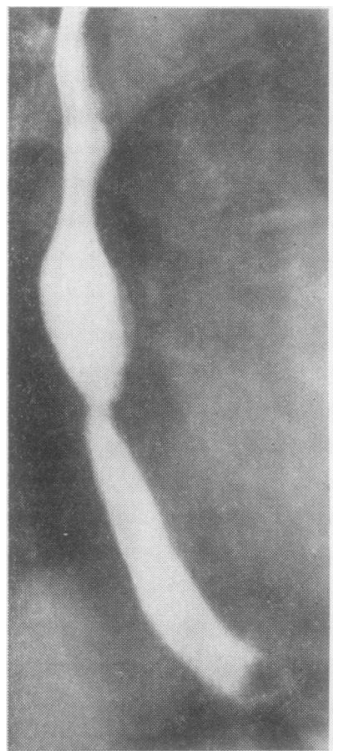

FIG. 7. Case 7. A long tubular hiatus hernia just below the stricture.

Operation A hernia was found and repaired. The hernia extended to just below the stricture.

CASE 8 E.D.. a man aged 79, was transferred from $\frac{0}{3}$ another hospital, complaining of dysphagia for solids and liquids for the past two months. He was losing weight.

A barium meal was performed before his transfer 을 and was reported as showing an irregular narrowing in $D$ the lower end of the oesophagus (in its lower third). almost certainly due to malignancy ; no hiatus hernia was seen.

He was admitted to Harefield Hospital on 11 January $N$ 1965.

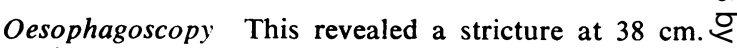
A biopsy was taken.

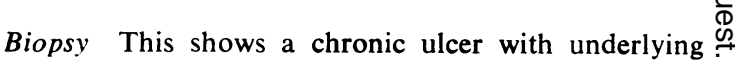
fibrosis.

Barium meal (Fig. 8) This revealed a hiatus hernia which was best demonstrated by a swallow in the $\frac{C}{\mathbb{D}}$ prone oblique position. There was no reflux above the $\varrho$ stricture, but reflux occurred into the lower tubular $\underset{<}{\sigma}$ gullet. 


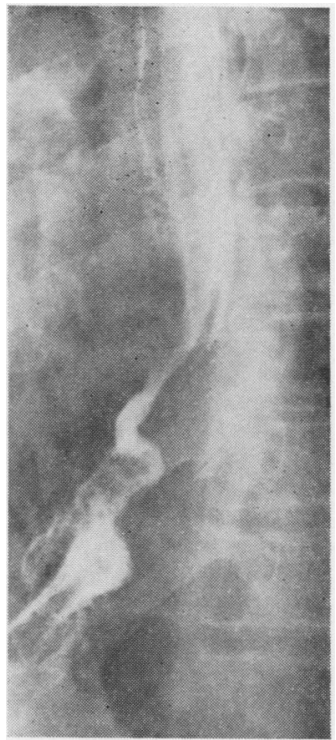

FIG. 8. Case 8. The gastric mucosa above the diaphragm is easily recognizable. The upper part of the hernia is becoming tubular in shape.

This case demonstrates how easily some herniae may be missed without suitable positioning. The hernia is obvious on the barium films taken at Harefield Hospital. Its total extent, however, is important and, although slightly saccular just above the diaphragm, the upper part of the hernia is becoming tubular in shape.

CASE 9 M.P., a woman aged 43, had had dysphagia since childhood. There was a long history of epigastric pain, relieved by alkalis. The pain was made worse by eating and by lying down. Over the past few months the pain had increased and solid food was sticking at the upper sternal level.

Barium meal (Fig. 9) This showed a stricture, below which there was a hernia which was tubular in shape. An ulcer was present at the stricture. There was no reflux.

The interesting feature in this case is the film showing the tubular shape of the lower gullet. A biopsy was taken from this region at operation, and the histological report was 'chronic non-specific inflammation of the gastric mucosa' (Figs $10 \mathrm{a}$ and $\mathrm{b}$ ).

This hernia was repaired at operation and it extended to a point just below the stricture.

CASE 10 B.D., a man aged 20, was referred to St. Mary's Hospital from elsewhere on 14 September 1964 because of six months' history of food sticking in the upper chest. This was relieved by oesophageal dilatation on two separate occasions. Before his admission the patient had had an Anderson-Hynes pyloroplasty.

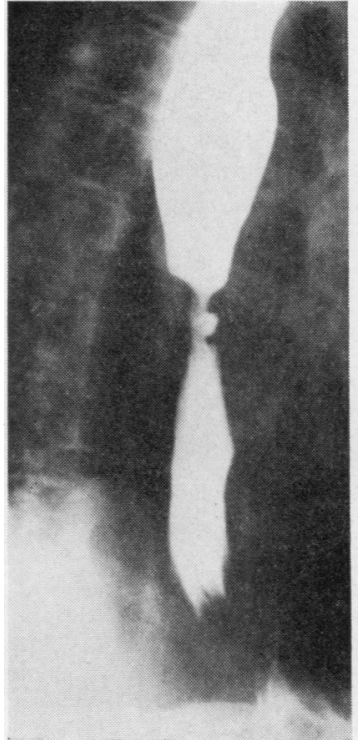

FIG. 9. Case 9. Stricture with ulceration and long tubular hernia.

Due to persistent post-operative vomiting, a nasogastric tube was inserted, and the dysphagia dated from its removal. It was thought before his admission that the indwelling tube, which had been in situ for one week, was responsible for the stricture.

Barium swallow (Fig. 11) The gullet below the stricture was in fact a tubular hiatus hernia. The stricture was considered to be due to gastro-oesophageal reflux from this hernia.

Operation (22 October 1964) The hernia was found to extend up to the stricture, and a biopsy was taken just below the stricture.

Biopsy Normal glandular gastric mucosa was found (Figs $12 \mathrm{a}$ and $\mathrm{b}$ ).

\section{DISCUSSION}

The features common to all the cases described are a stricture of the oesophagus, usually in the lower third, and the presence of a tubular-shaped gullet below it, which radiologically looked like the oesophagus. It seems possible that some cases diagnosed as simple peptic oesophagitis, but with strictures at a rather high level, may in fact be associated with this type of tubular herniation of the stomach.

In the cases reported here the findings could be interpreted as due to the presence of Barrett epithelium if the lower gullet had not been 


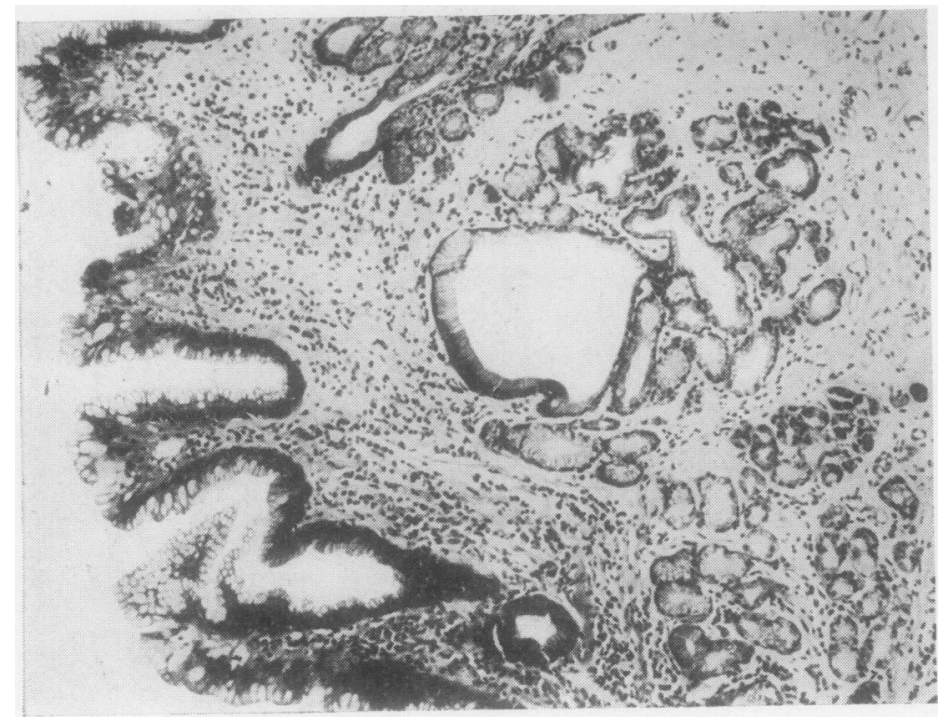

FIG. 10. Case 9. (a) Gastric mucosa is $(\times 90)$; (b) gastric mucosa $(\times 294)$.

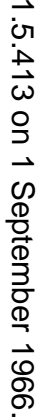

(a)

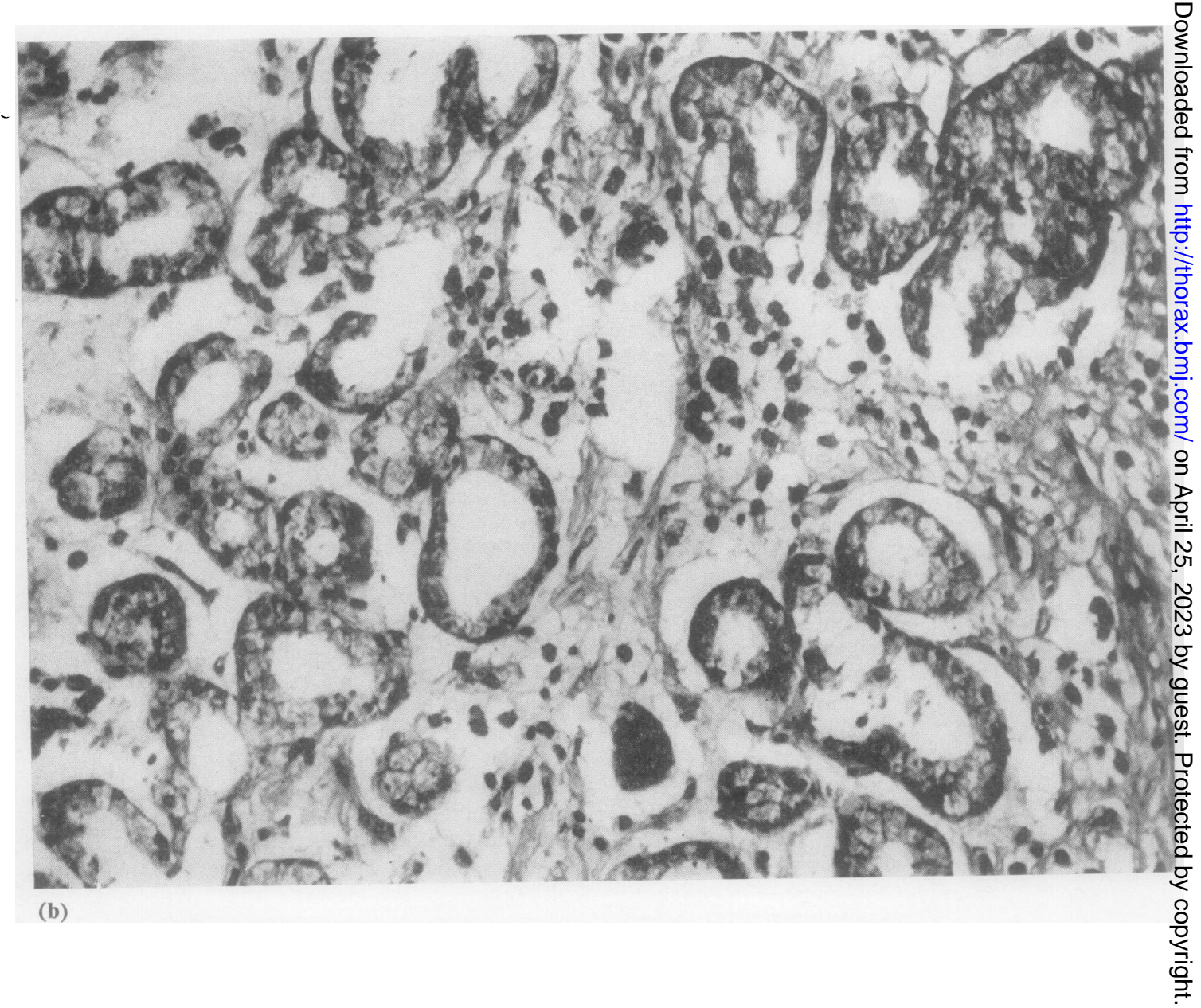




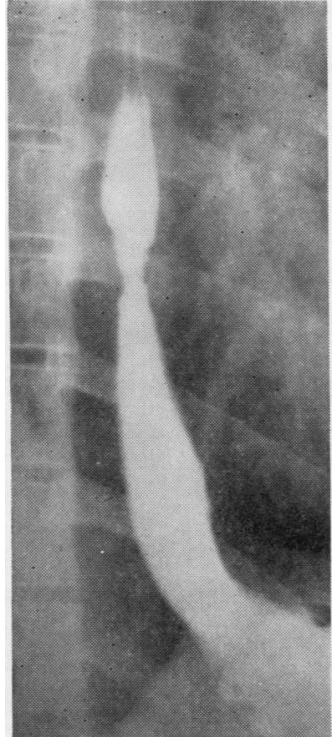

FIG. 11. Case 10. Below the stricture is a long tubular hiatus hernia.

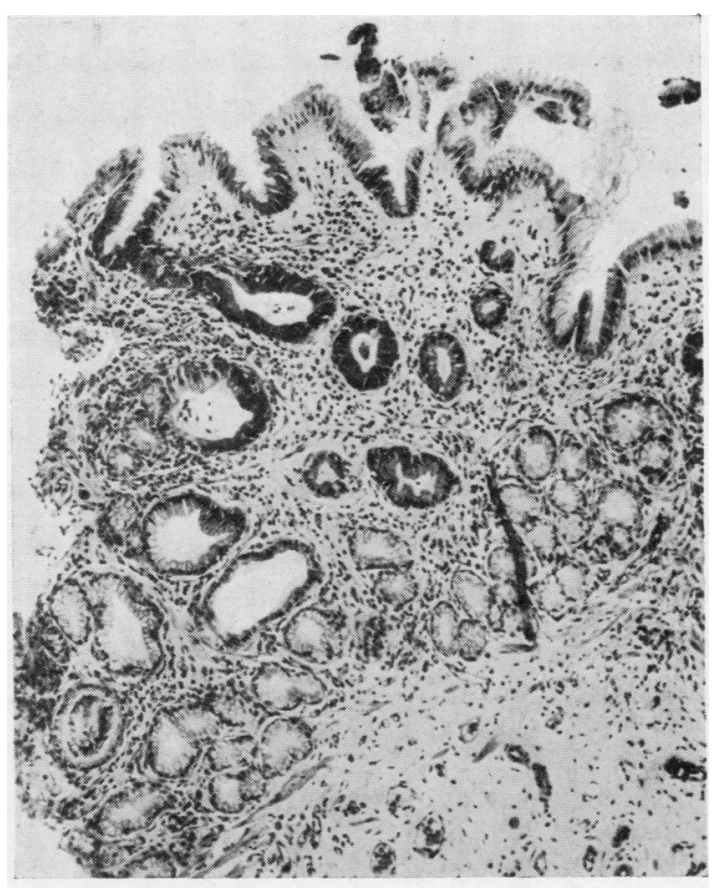

FIG. $12 \mathrm{a}$

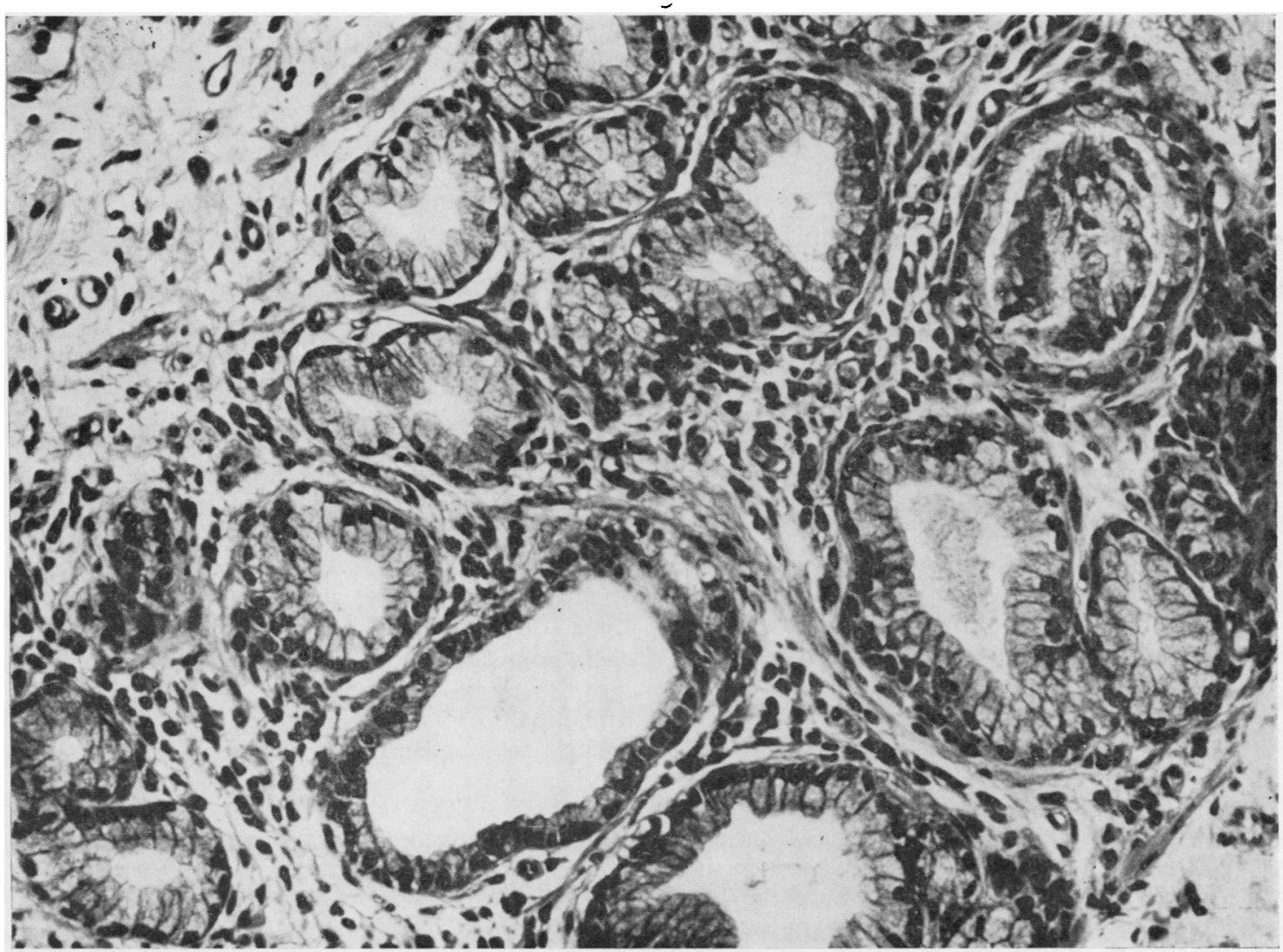

FIG. $12 \mathrm{~b}$

FIG. 12. Case 10. (a) Gastric mucosa ( $\times$ 90); (b) gastric mucosa $(\times 294)$. 
proved in all cases at operation to consist entirely of herniated stomach. Cohen, Wolf, Som, and Janowitz (1963) correlated the manometric, oesophagoscopic, and radiological findings in the columnar-lined oesophagus, i.e., the Barrett syndrome. They demonstrated continuous peristaltic waves in response to swallowing, down to the stomach, indicating that the columnar-lined segment had the motor characteristics of the oesophagus. There was no discontinuity between the squamous and columnar-lined segments. The evidence also indicated that the terminal portion of the columnar-lined segment was the site of a sphincter area, as would be anticipated if the columnar-lined segment functioned as oesophagus.

During screening, in the cases reported here, the lower part of the gullet behaved radiologically like the oesophagus, and there appeared to be a sphincter at the hiatus. Mann, Greenwood, and Ellis (1964) reviewed the oesophago-gastric junction and acknowledged the presence of a physiological sphincter which straddles the hiatus. They thought, however, that the diaphragm was not part of this sphincter, but indirectly it may aggravate or cause reflux by trapping secretions under pressure in the pouch of a hiatus hernia. This action of the diaphragm, present in these reported cases, is familiar to all radiologists.

Pierce and Creamer (1963) described six cases of oesophageal stricture occurring above a columnar-lined oesophagus. They stated that the gullet below the stricture often showed nonperistaltic contractions in which the whole segment below the stricture contracted and emptied at the same time, rather more frequently than in a normal oesophagus. Rippling or tertiary contractions were never seen. In all cases the columnar segment of the oesophagus below the stricture was wider than normal. This was especially noticeable at the lower end, where the oesophagus would intermittently dilate until it became as wide as the hernia, the two structures then forming a uniform tube tapering towards the stricture. The gastrooesophageal junction seemed to be more distensible than normal, dilating to the full diameter of the hernia and the lower oesophagus. Even when fully dilated there was no evidence of any intervening ring constriction.

Somewhat similar findings were present in some of the 10 cases reported here, where the lower gullet was totally a tubular hernia. The whole of this part of the gullet occasionally contracted and emptied at the same time. There were no rippling movements or tertiary contractions. However, this lower segment, when distended, is wider than
the normal oesophagus.

There are certain features which enable the radiologist to recognize the gastric origin of the ${ }^{\infty}$ lower gullet. These are:

(1) The greater distensibility of the part. When care is taken to fill the lower part of the gullet in the prone or supine oblique position, and to apply abdominal compression, this part of the gullet frequently distends more than the normal oeso- $-\frac{-}{\text { or }}$ phagus.

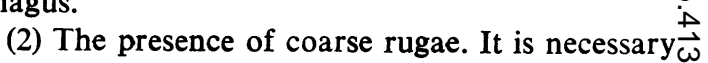
to get a good mucosal view of the lower gullet.o This is best done by means of a swallow in the prone oblique position. The rugae are coarser incs the gastric segment than in the oesophagus.

(3) The presence of mucosal folds diverging $\mathbb{\mathbb { D }}$ downwards at the hiatus suggests that this is gastric mucosa. Oesophageal mucosa converges as it approaches the hiatus again. A prone oblique $\vec{\bullet}$ swallow with films taken after the passage of the barium bolus will demonstrate the mucosal folds.

(4) Frequently a 'transition groove' is seen be-o tween the oesophagus and the hernia, e.g., Shatzis ring.

The Barrett syndrome is diagnosed by oeso-कू phageal biopsy when columnar-lined epithelium is found containing few oxyntic cells. In the caseso reported here the biopsy report in many of them showed columnar epithelium, gastric in type, and containing oxyntic cells (Figs 10 and 12). Gold man and Beckman (1960) point out that the gastric cardiac glands are similar histologically to columnar epithelium in the lower oesophagus. Invari- $x$ ably the pathological request form would be labelled 'lower end of the oesophagus'. It would not be surprising, therefore, if 'gastric mucosa' ectopic in the oesophagus were reported.

The similarity between the two conditions of Barrett syndrome and tubular herniation is also evident histologically, and care must be taken to look for oxyntic and peptic cells.

In none of the cases reported here was theron any histological proof that the mucosa was inflamed oesophageal mucosa, regenerating as
gastric type epithelium.

It appears, therefore, that when an inflam matory oesophageal stricture is found, in the absence of any obvious herniation, careful radiological examination should be performed with suitable posturing and with abdominal compres-ब sion to avoid missing a tubular gastric herniation $\frac{\mathrm{D}}{\mathrm{P}}$ If the appropriate films are not taken the case wilp closely resemble the Barrett syndrome. In theso cases of tubular herniation, bouginage alone? 
though dilating the stricture, merely aggravates the oesophagitis by encouraging further reflux. Strictures of quite considerable length can be produced by this series of events.

\section{SUMMARY}

Ten cases of stricture of the lower gullet are discussed. These had gastric mucosa below the stricture in a part radiologically easily mistaken for the oesophagus. In many of these a carcinoma was misdiagnosed or strongly suggested. All the cases were due to stomach herniation and the herniated portion had become tubular in shape. If appropriate views are not taken radiologically the appearances can be confused with the Barrett syndrome.

As most of these cases were collected over a relatively short period of time it appears that this type of lesion is not uncommon.

I am indebted to Sir Thomas Holmes Sellors, Mr. J. W. Jackson, and Mr. K. Ross, of Harefield Hospital, and Mr. L. L. Bromley, of St. Mary's Hospital, W.2, for permitting publication of these cases under their care and for their help and encouragement in the preparation of this paper. I wish to express my thanks to Dr. Nassau, of the Pathology Department, Harefield Hospital, for biopsy reports and to Dr. E. Wright, of the Pathology Department, St. Mary's Hospital, W.2, for biopsy reports and for supplying the prints of the microscopic sections. Dr. P. Cardew, of the Photographic Department, St. Mary's Hospital, kindly made the prints of the radiographs.

I am also indebted to Dr. F. Starer, who made many valuable suggestions for the presentation of the radiological findings.

\section{REFERENCES}

Allison, P. R., and Johnstone, A. S. (1953). The oesophagus lined with gastric mucous membrane. Thorax, 8, 87.

Barrett, N. R. (1950). Chronic peptic ulcer of the oesophagus and 'oesophagitis'. Brit. J. Surg., 38, 175.

(1957). Surgery, 41, 881.

(1960). Hiatus hernia. Brit. med. J., 2, 247.

Cohen, B. R., Wolf, B. S., Som, M., and Janowitz, H. D. (1963). Correlation of manometric, oesophagoscopic and radiological findings in the columnar-lined gullet. (Barrett syndrome.) Gut, 4, 406.

Goldman, N. C., and Beckman, R. C. (1960). Barrett syndrome. Case report with discussion about concepts of pathogenesis. Gastroenterology, 39, 104.

Mann, C. V., Greenwood, R. K., and Ellis, H. F. (1964). The esophagogastric junction. Surg. Gynec. Obstet., $118,853$.

Pierce, J. W., and Creamer, B. (1963). The diagnosis of the columnar lined oesophagus. Clin. Radiol., 14, 64. 